\title{
INFLUENCE OF PLASTIC DEFORMATION PROCESS ON THE STRUCTURE AND PROPERTIES OF ALLOY WE43
}

\begin{abstract}
The paper describes the results of structure and properties tests of flat bars made of alloy WE43 obtained in the process of extrusion with the use of KOBO method. An analysis of structure changes was conducted both in initial state and after plastic deformation.

A quantitative analysis of the material was also conducted with the use of METILO program. The paper also presents results of mechanical tests marked in the uniaxial tensile testing in room temperature and in elevated temperature for achieved flat bars. Fractographic tests were conducted after tensile test in order to determine the mechanism of cracking.
\end{abstract}

Keywords: alloy WE43, microstructure, tensile test, fractographic analysis of fractures

\section{Introduction}

Nowadays, a growing demand is observed in aviation industry for spare parts made of light alloys which are sufficiently stiff and resistant. Due to their low weight magnesium alloys are attractive materials for such applications. So far, the application of magnesium alloys was limited mainly to products achieved in the method of casting which sometimes limited the range of their application. Since the methods of plastic treatment started to be used, magnesium alloys can serve as an interesting alternative to the currently applied materials. Technology of plastic treatment of magnesium alloys is challenging. Due to low plasticity of those materials in room temperature the parameters of plastic treatment process need to be a satisfying compromise between costs and quality of the products. Therefore, scientists search for alternative methods of plastic shaping of magnesium alloys. The method of particular interest here is so-called unconventional processes of plastic treatment. In tests of SPD (severe plastic deformation) processes there are two main tendencies to be distinguished. First is shaping the material in conditions of cold plastic treatment and the second is the analysis of possibilities of application of SPD processes in elevated temperatures. This tendency refers also to the tests of magnesium alloys, for example tests conducted for alloy AZ31 [1]. Those tests have shown that with the application of ECAP process a triple increase of true strain value for alloy AZ31 was achieved. A decrease of flow stress value was also observed in comparison to conventionally shaped material. Those results confirm the beneficial effects resulting from the application of SPD processes in elevated temperatures in shaping magnesium alloys. Group Mg-Y-Re-Zr includes alloy WE43 which, thanks to its properties, is plastically deformed mainly in the extrusion processes [5-6]. Construction elements which are prepared from WE43 alloy can be by $20-30 \%$ lighter than their equivalents prepared from aluminium alloys. Application of this alloy in aviation industry and automotive industry provides the proper resistance-to-weight ratio without the significant loss of properties in the required temperature. Attempts were made to shape the alloy WE43 with the use of extrusion in $\mathrm{KOBO}$ method which is among the unconventional groups of metal and alloy deformation methods with very big degrees of deformation. The method is based on the application of the additional reversible torsion of die by assumed angle with stated frequency. Achieved products/semi-products are characterised with high resistance and good plastic properties [5-9]. The paper presents the results concerning the influence of the process of extrusion with the use of KOBO method on the structure and properties of the achieved flat bars from alloy WE43.

\section{Experimental procedure}

Materials for tests were ingots from magnesium alloy WE43 with chemical composition (Y- 4\%, Nd- 2\%, RE- 1\%, $\mathrm{Zr}-0.45 \%$ mass.). As a result of casting process ingots sized $65 \times 40 \mathrm{~mm}$ were achieved and underwent a process of extrusion to diameter of $40 \mathrm{~mm}$ (Fig. 1). The alloy was smelted in singlecompartment vacuum induction lab furnace VSG 02 by Balzers Company. Casting was conducted in argon atmosphere. Plastic shaping test of examined alloys was conducted in $\mathrm{KOBO}$ process in room temperature. The method is based on extrusion of the material with additional plastic deformation caused by variable torsion of die towards the product. Two methods of extrusion were used. The first method was based on the extrusion of the sample with sideways flow of the material and the second with concurrent flow of the material [4]. The results of conducted tests were flat bars with width of $12 \mathrm{~mm}$ and height of $4 \mathrm{~mm}$. An analysis of structure changes after casting

\footnotetext{
* SILESIAN UNIVERSITY OF TECHNOLOGY, FACULTY OF MATERIAL SCIENCE AND METALLURGY, 8 KRASIŃSKIEGO STR., 40-019 KATOWICE, POLAND

* Corresponding author: iwona.bednarczyk@polsl.pl
} 


\section{Results and discussion}

light microscope. Tests of properties of achieved flat bars were conducted on tension testing machine ZWIK/Z100. Samples from tested alloy were stretched in room and in elevated temperatures. Samples with length base of $32 \mathrm{~mm}$ were used in the tests. Fractographic tests were conducted to determine the character of the fracture with the use of scanning microscope Hitachi S-4200. Hardness tests with the use of Vickers method were conducted on hardness tester ZWICK with load of $20 \mathrm{~N}$ in condition after casting and after extrusion. Structures of both samples underwent quantitative analysis and the stereological parameters of grain were marked with the use of program METILO [8]. Measurement of grain size was conducted with the use of surface method based on the pictures registered by light and scanning microscopes (Fig. 2).

a)

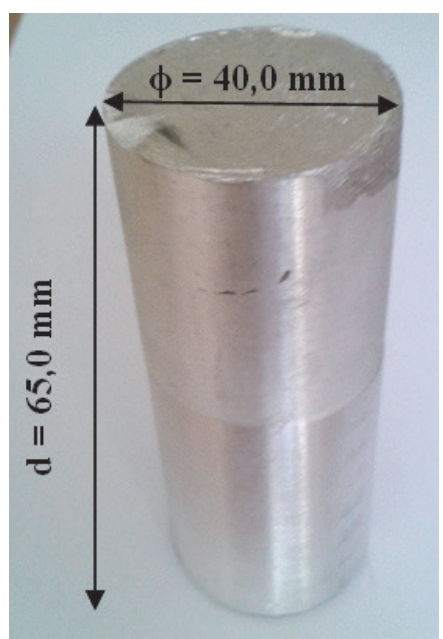

b)

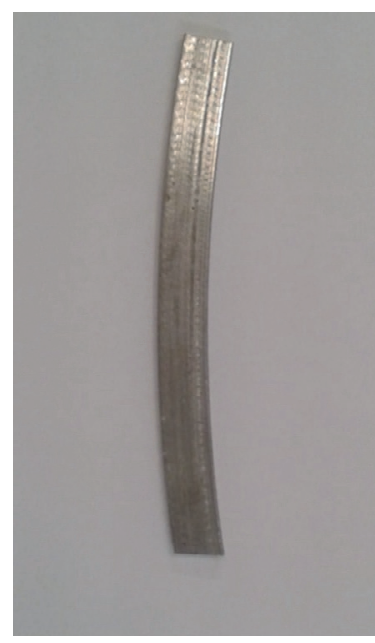

Fig. 1. a) ignot after casting, b) flats obtained by extruding
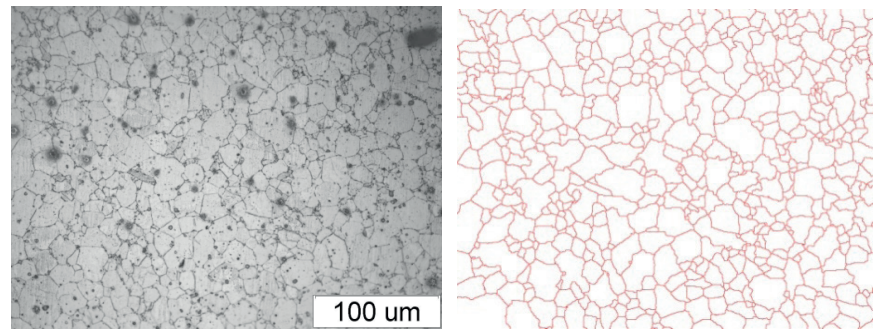

Fig. 2. The analyzed image and the binary image of detection grain boundaries a)

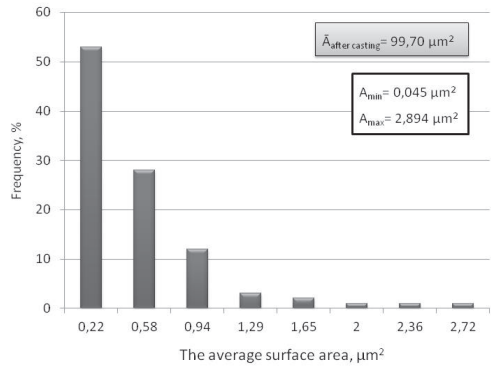

Figure 3 shows microstructure of alloy WE43 after casting process and after plastic deformation. Microstructure of tested alloy after casting process was characterised with coarse-grained structure with varied grain sizes (Fig. 3a) and after deformation process the microstructure of alloy showed significant fineness of structure (Fig. 3b). It was confirmed by conducting quantitative analysis of the structure where the average diameter of grain in initial state after casting was 10.7 $\mu \mathrm{m}$ and in case of sample after plastic treatment decreased to the value of $0.9 \mu \mathrm{m}$. Besides average grain diameter the average grain surface area was also marked together with shape factor for both samples and the results are presented in the form of diagram in Fig. 4. As the picture shows the area distribution of plane section of sample (fig.4a) the area of sample after plastic treatment decreased by 100 times in comparison with the sample after casting (for cast sample $\overline{\mathrm{A}}=99.70 \mu \mathrm{m}^{2}$, for sample after deformation $\overline{\mathrm{A}}=0.51 \mu \mathrm{m}^{2}$ ). Grain size in sample after extrusion varies between 0.045 to $2.894 \mu \mathrm{m}^{2}$ and most grains belongs to the lower scale of surface area. On the basis of the next diagram (Fig. 4b) it can be stated that the structure after extrusion is a structure with grain of more equiaxial type than after casting which is presented by classical configuration factor (for sample after deformation the configuration factor was 0.735 ; for cast sample -0.58 ). a)

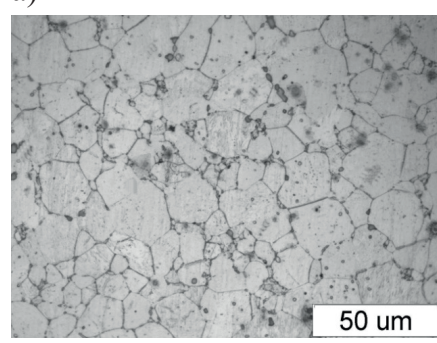

b)

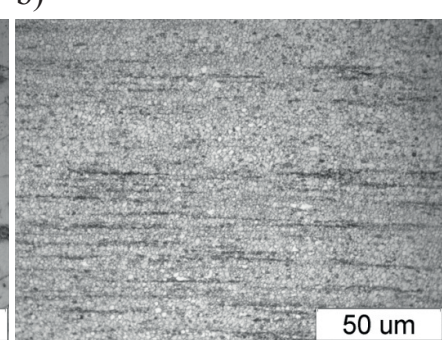

Fig. 3. Microstructure of alloy: a) after casting, b) after hot plastic deformation

Stress-strain curves for tested alloy in room temperature and in elevated temperature are presented in figure 5. Conducted tension tests allowed for marking the mechanical properties of the tested alloy. Conducted tension test both in room and elevated temperatures brought satisfactory results. There was

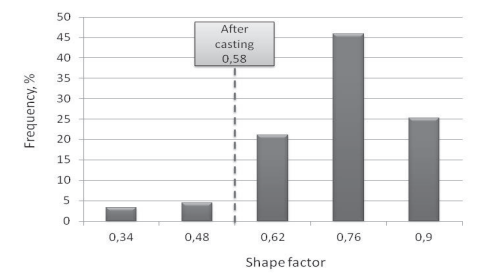

Fig. 4. a) The average surface area, b) the shape index grain size of the alloy WE43 after the extrusion process by KOBO 
no decrease of resistance observed in elevated temperature. Samples after resistance tests underwent fractographic tests in order to determine the character of fracture which formed. The fracture area of alloy WE43 deformed in room temperature is a ductile fracture (Fig. 6a) whereas fractographic tests for alloy WE43 in temperature of $200^{\circ} \mathrm{C}$ show the presence of mixedtype fractures with visible ductile and brittle areas (Fig. 6b). Hardness tests were conducted with the use of Vickers method for ingots and flat bars from alloy WE43. Achieved results of tests show the increase of hardness of tested alloy WE43 after extrusion test with the use of KOBO method (Fig. 7.).

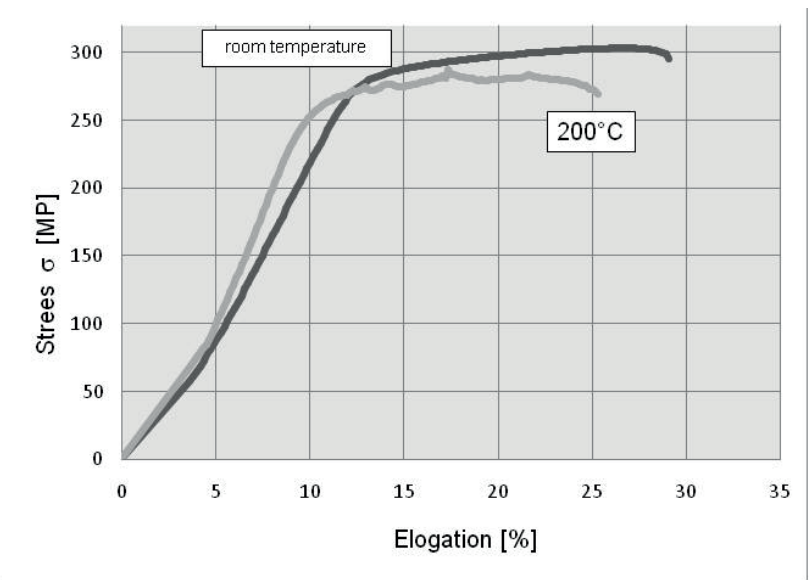

Fig. 5. Strain curvefor the investigated alloy: a) room temperature, b) increased $200^{\circ} \mathrm{C}$

a)

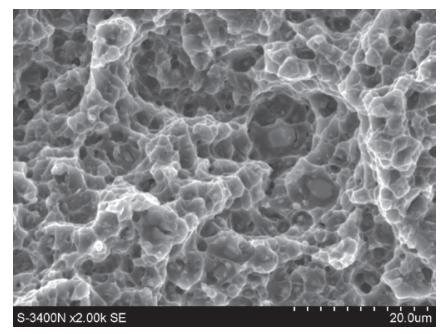

Fig. 6. Fractures surface after the tensile test at temperature: a) a room, b) increased $200^{\circ} \mathrm{C}$

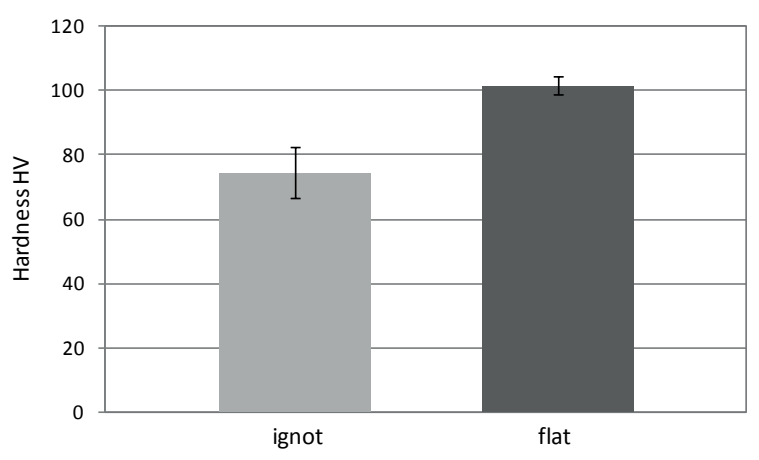

Fig. 7. Hardness of the investigated alloy

\section{Conclusions}

The choice of plastic treatment technology of construction elements requires precise determination of the influence of process parameters on the plasticity and microstructure of alloys. It is an important aspect during designing the products made of magnesium alloys meant for construction elements for aviation industry which replace conventional materials. Shaping flat bars with extrusion method in complex state of deformation allowed for achievement of significant fineness of microstructure for alloy WE43 in comparison with condition after casting. Conducted quantitative analysis of both structures allowed to describe the observed changes in numbers. Marked average grain diameter in condition after casting was $10.7 \mu \mathrm{m}$ and in case of sample after plastic treatment decreased to the value of $0.9 \mu \mathrm{m}$. Besides average grain diameter the average grain surface area was also marked and it was stated that after plastic treatment the area decreased by 100 times in comparison with the sample after casting (for cast sample $\bar{A}=99,70 \mu \mathrm{m}^{2}$, for sample after deformation $\overline{\mathrm{A}}=0,51 \mu \mathrm{m}^{2}$ ). Tensile test results show that alloy WE43 shows beneficial resistance and plastic properties. It is characterised with comparable resistance in both room and elevated temperatures which proves the stability of the microstructure. Further tests will concentrate on getting to know the structural phenomena which occur in the structure of tested alloy after plastic deformation with the use of transmission and scanning-transmission microscopy techniques.

\section{Acknowledgements}

Financial support of Structural Funds in the Operational Programme - Innovative Economy (IE OP) financed from the European Regional Development Fund - Project Modern material technologies in aerospace industry, No POIG.01.01.02-00-015/08-00 is grate-fully acknowledged

\section{REFERENCES}

[1] W.J. Kim, Y.K. Sa: Micro extrusion of ECAP processed alloy for production of high strength magnesium micro-gears, Scripta Materialia 54, 2006.

[2] E. Hadasik E., D. Kuc, G. Niewielski, R. Śliwa, Development of magnesium alloys for plastic treatment, MetallurgistMetallurgical News 8, 580-584 (2010).

[3] E. Hadasik, D. Kuc, Plastic treatment of magnesium alloys, Plastic treatment of metals, Metal Forming 24, 2, 131-147 (2013).

[4] W. Bochniak, A. Korbel, P. Ostachowski, S. Źiółkowicz, J. Borowski, Extrusion of metals and alloys with the use of KOBO method, Plastic treatment 24, 2,83-97(2013).

[5] A. Korbel, W. Bochniak, J. Borowski, L. Błaż, P. Ostachowski, M. Lagoda,Anomalies in precipitation hardening process of 7075 aluminum alloy extruded by KOBO method, Journal of

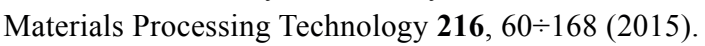

[6] A. Korbel, W. Bochniak, Lüders deformation and superplastic flow of metals extruded by KOBO method. Philosophical Magazine 93, 15, 1883 $\div 1913$ (2013).

[7] A. Korbel, W. Bochniak P. Ostachowski, A. Paliborek, Mechanical properties of aluminum extruded by KOBO method with direct and lateral outflow. International Journal of Materials Research 102, 10, 974-79 (2013). 
[8] J. Szala, Application of computer picture analysis methods to quantitative assessment of structure in materials, Scientific Journals of Silesian University of Technology, Series Metallurgy, Gliwice 2008.
[9] A. Mrugała, I. Bednarczyk, Characteristics of microstructure and properties of flat bar extruded from light alloys with the use of method in complex state of strain, Hutnik-WiadomościHutnicze 8, 533-536 (2015). 